九州大学学術情報リポジトリ

Kyushu University Institutional Repository

\title{
Changes in The Dynamic and Static MOE of Furfuryl Alcohol-Treated Wood
}

\section{Kang, Chun-Won}

Department of Housing Environmental Design, and ResearchInstitute of Human Ecology, College of Human Ecology, Chonbuk National University

Jin, Taiquan

Department of Housing Environmental Design, and ResearchInstitute of Human Ecology, College of Human Ecology, Chonbuk National University

Park, Hee-Jun

Department of Housing Environmental Design, and ResearchInstitute of Human Ecology, College of Human Ecology, Chonbuk National University

Wen, Ming-Yu

Department of Housing Environmental Design, and ResearchInstitute of Human Ecology, College of Human Ecology, Chonbuk National University

他

https://doi.org/10.5109/1526308

出版情報：九州大学大学院農学研究院紀要. 60 (1)，pp.203-207，2015-02-27. Faculty of Agriculture, Kyushu University

バージョン :

権利関係 : 


\title{
Changes in The Dynamic and Static MOE of Furfuryl Alcohol-Treated Wood
}

\author{
Chun-Won KANG ${ }^{1}$, Taiquan JIN $^{1}{ }^{*}$, Hee-Jun PARK ${ }^{1}$, Ming-Yu WEN ${ }^{1}$, \\ Ho-Yang KANG ${ }^{2}$ and Junji MATSUMURA
}

\author{
Laboratory of Wood Science, Division of Sustainable Bioresources Science, \\ Department of Agro-environmental Sciences, Faculty of Agriculture, \\ Kyushu University, Fukuoka 812-8581, Japan \\ (Received October 29, 2014 and accepted November 14, 2014)
}

\begin{abstract}
To assess changes in the mechanical properties of wood treated with furfuryl alcohol, the static modulus of elasticity, the dynamic modulus of elasticity and some physical properties of pine and larch wood were estimated before and after furfuryl alcohol treatment. The possibility of reducing floor noise by using furfuryl alcohol-treated wood was also evaluated.

In comparison to untreated specimens, furfuryl alcohol-treated wood exhibited a color change from yellow to slightly brown, and swelling and water absorption ratios were significantly reduced. Furthermore, the specific gravity, static MOE and dynamic MOE were enhanced while the natural frequency was reduced. The correlation coefficient between the dynamic modulus of elasticity and the static modulus of elasticity for furfuryl alcohol-treated specimens and for control specimens were 0.90 and 0.92 , respectively. The dynamic MOE to specific gravity ratio (dMOE/r) and the static MOE to density ratio (sMOE/r) both decreased as a result of furfuryl alcohol treatment. The furfuryl alcohol-treated wood could contribute to a decrease in noise if used as flooring material.
\end{abstract}

Key words: furfuryl alcohol treatment, static MOE, dynamic MOE, color change, water absorption

\section{INTRODUCTION}

Wood is a hygroscopic material in that its dimensions change in humid environments and it is vulnerable to mold and other infestations. To overcome these disadvantages, several wood modification techniques have emerged, including heating, surface densification, chemical bulking of cell walls, polymer impregnation, and chemical alteration of cell composition, among other methods (Hills, 2006).

Furfurylation is a specific type of impregnation modification that uses furfuryl alcohol. When wood is treated with furfuryl alcohol, polymerization occurs, the basic chemistry of which has been established (Chuang et al., 1984; Gonza lez et al. 1992; Gonza lez et al., 2002; Maciel et al., 1982). Polymerization reduces equilibrium moisture content and increases dimensional stability and biological durability (Hills, 2006; Nordstierna et al., 2008; Lande et al., 2004, Esteves et al., 2011). Furfurylation modification causes several positive changes in the mechanical properties of wood. Esteves et al. (2011) suggested that density and hardness increase significantly in furfuryl alcohol-treated Pinus pinaster wood. However, they also found that the MOE of furfuryl alcohol-treated wood was similar to that of untreated wood and the MOR increased slightly. Epmeier et al. (2004) reported similar results. In contrast, the impact bending strength of wood is decreased when treated with furfuryl alcohol

${ }^{1}$ Department of Housing Environmental Design, and Research Institute of Human Ecology, College of Human Ecology, Chonbuk National University, Jeonju 561-756, Korea

${ }^{2}$ Department of Biobased Materials, College of Agriculture and Life Sciences, Chungnam National University, Daejeon 305764 , Korea

* Corresponding author (E-mail: taiquan2013@naver.com)
(Lande et al., 2004).

Furfurylation darkens the color of the wood, which could allow furfuryl-treated softwood to replace tropical hardwood. Furthermore, because of its dimensional stability, furfurylated softwood could be used as flooring material. Several studies concerning the reduction of floor noise have recently emerged. Norimoto et al. (1992) demonstrated that quality sounding boards for pianos have a low internal friction to dynamic MOE ratio (Q-1/ $\mathrm{E}^{\prime}$ ), and that this value is strongly correlated with the dynamic MOE to density ratio (E'/r). These results suggest that either the static or dynamic MOE to density ratio could be used to estimate floor noise levels. Other studies have found that static MOE and dynamic MOE are highly correlated. Lee \& Huang (1997) studied the adoption of resonance frequency by transverse vibration method and density to estimate the dynamic modulus of elasticity (dMOE) and Park and Byeon (2006) reported that the correlation coefficient between static bending strength and the dynamic modulus measured by resonant frequency ranged from 0.811 to 0.947 in laminated timber. Cho (2000) found that the correlation coefficient between static MOE and dynamic MOE by the strength variation of Japanese cedar was 0.82 .

The purpose of this study was to assess the property changes related to furfurylation of wood. We also evaluated the possibility of reducing floor noise by using furfurylated wood, given the changes in density, static MOE and dynamic MOE. The study was limited to small specimens. In addition, a curing temperature of 130 was adopted for furfuryl alcohol treatment, as determined by pre-experiments. 


\section{MATERIALS AND METHODS}

\section{Sample specimen}

Defect-free, straight-grained pine wood (Pinus densiflora S. et Z.) and larch wood (Larix kaemferi carr) test specimens were prepared through sawing and planing. The test specimens were cut from timber which was first oven-dried at $60^{\circ} \mathrm{C}$ and thereafter conditioned to stable moisture content (MC). Test specimens measured nominally $20(\mathrm{~h}) \times 20(\mathrm{w}) \times 320(\mathrm{l}) \mathrm{mm}^{3}$ at $13 \% \mathrm{MC}$. Before impregnation, all specimens were oven dried for 48 hours at $103 \pm 1^{\circ} \mathrm{C}$. Then, initial and final oven-dried weights and sizes of the specimens were measured. For static and dynamic MOE estimation, the same specimen was analyzed both before and after treatment. Finally, Brinell hardness was estimated for the control and treated specimens.

\section{Impregnation}

All samples went through the same impregnation procedure. The samples were placed in an autoclave and vacuum $(76 \mathrm{cmHg} . \mathrm{V})$ was applied for 30 minutes. The furfuryl alcohol was then moved into the treatment chamber and pressure (1.38 MPa) was applied for 2 hours. After the samples were removed from the autoclave, they were wiped clean of excess liquid and cured at $130^{\circ} \mathrm{C}$ for 2 hours.

\section{Color measurement}

Specimen color was measured using a spectrophotometer (CR-400/410, KONICA MINOLTA) with a D65 light source. In this color space, color is defined by its Cartesian chromatic coordinates. The CIE L*a*b* color parameters $\left(\mathrm{L}^{*}, \mathrm{a}^{*}, \mathrm{~b}^{*}\right)$ were used to express color change. From the $\mathrm{L}^{*}, \mathrm{a}^{*}$, and $\mathrm{b}^{*}$ values obtained, the total color difference $(\Delta \mathrm{E})$ was calculated using following formula:

$$
\Delta E=\left(\Delta L^{2}+\Delta a^{2}+\Delta b^{2}\right)^{1 / 2}
$$

where $\Delta \mathrm{L}, \Delta \mathrm{a}$ and $\Delta \mathrm{b}$ are the changes between before and after treatment values.

\section{Dimensional stability}

Water absorption and radial and tangential direction swelling ratios were measured after soaking the ovendried samples in distilled water for 8 weeks. The crosssectional and longitudinal dimensions and volume (v) of the saturated specimens were then determined, after which all specimens were oven-dried to a constant weight.

\section{Dynamic modulus of elasticity}

The dynamic modulus of elasticity was determined by the free-free suspended beam technique, in which a pick-up accelerometer ( $\mathrm{B} \& \mathrm{~K}$ ) is fastened to the center of the specimen and the specimen is struck lightly on one end with an impulse hammer (Type 8203, B \& K). The impact causes the specimen to vibrate and the signal produced by the accelerometer is then transformed by an FFT analyzer (Type 3065, B \& K) and processed using computer software, generating the estimated reso- nant frequency $\left(\mathrm{f}_{0}\right)$. From the $\mathrm{f}_{0}$, the resonant frequency (f) was corrected to eliminate the influence of shear deflection (Kataoka and Ono, 1975). The dynamic modulus of elasticity (dMOE) was calculated using the following formula.
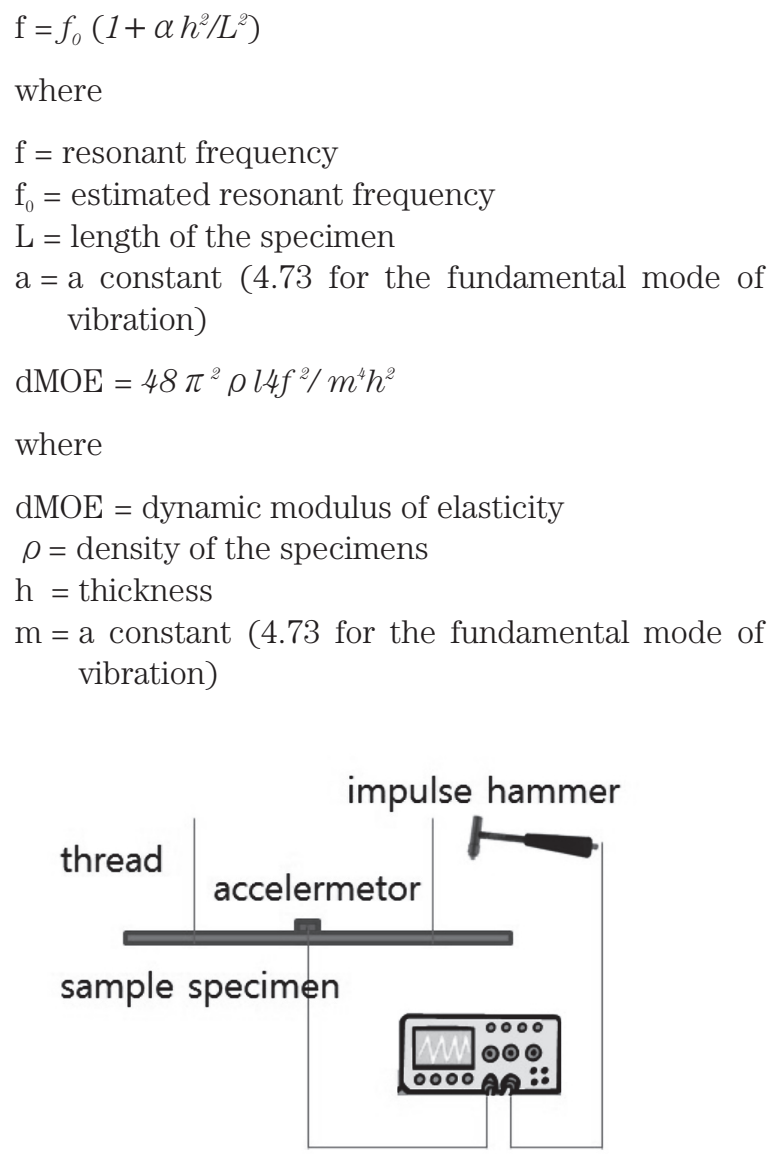

Fig. 1. Schematic diagram for the dynamic MOE measuring apparatus.

\section{Static modulus of elasticity in bending}

Static three-point bending tests were performed using a universal testing machine (AGS-1000G, Shimadzu Corporation). Both untreated and furfural alcohol treated-specimens were loaded in the radial direction for the bending tests. The span (L) was $28 \mathrm{~cm}$ and the cross head was advanced at $10 \mathrm{~mm} / \mathrm{min}$. The proportional limit, ultimate load, and deflection were obtained from load-deflection curves, and the static MOE were calculated.

\section{Brinell hardness}

A steel ball was forced against the longitudinal-radial surface of control and furfural alcohol-treated wood by a Brinell hardness tester at $500 \mathrm{~N} / \mathrm{mm}^{2}$. The indentation load, indentation depth and indentation surface area were evaluated, and the Brinell hardness (HB) was determined using the following formula.

$$
\mathrm{H}_{\mathrm{B}}=2 P /(\pi D)\left(D-\left(\left(D^{2}-d^{2}\right)^{1 / 2}\right)\right)
$$

where 
$P=$ load,

$D=$ diameter of the steel ball,

$d=$ diameter of the indentation

\section{RESULTS AND DISCUSSION}

\section{Physical properties}

Furfuryl alcohol treatment caused several positive changes in the physical properties of pine and larch wood. We found that the average weight percentage gain (WPG) was 35.58\% for pine and 33.88\% for larch specimens after impregnation with furfuryl alcohol (Table 1). Treatment with furfuryl alcohol significantly reduced swelling and water absorption compared to untreated specimens. The water absorption (WA) values of untreated specimens were found to be $68.94 \%$ for Larch and $119.74 \%$ for pine after a 48 -hour immersion period in distilled water. After impregnation, the water absorption values decreased to $22.63 \%$ for larch and $39.88 \%$ for pine compare to untreated, respectively. Other studies have found similar results. However, furfuryl alcohol treatment caused the specimens to change color from yellow to slightly brown. The total color difference $(\Delta \mathrm{E})$ was 53.72 for Larch and 48.36 for Pine, respectively.

\section{Mechanical properties}

The density was higher and the Brinell hardness greater for the furfuryl alcohol-treated wood than for the control wood. The Brinell hardness of the control and treated woods were $1.78 \mathrm{MPa}$ and $4.91 \mathrm{MPa}$ for pine and $1.50 \mathrm{MPa}$ and 2.12 MPa for larch, respectively (Table 2). It is suggest that the treatment cause the wood to stiffen.
At the same conditions, the frequency of vibration is proportional to the material elasticity and is inversely proportional to the mass of the material. In this study, furfuryl alcohol treatment decreased the resonant frequency, which was proportional to weight gain by furfuryl alcohol treatment (Figure 2). Here, the $\mathrm{R}$ value was 0.46 , and was only slightly correlated. Although resonant frequency decreased, the dynamic MOE increased as a result of treatment. The strain of the dynamic MOE is relatively smaller than that of the static MOE, such that the value of the dynamic MOE may be influenced more by surface area than by the inner area of the vibrating body. Therefore, it is considered that surface stiffness produced by the furfural alcohol treatment caused the dynamic MOE enhancement.

As a result of furfuryl alcohol treatment, the static modulus of elasticity (sMOE) also increased. The static MOE of wood before and after the treatment was 7727 $\mathrm{MPa}$ and $8009 \mathrm{MPa}$ for pine and $8978 \mathrm{MPa}$ and $9997 \mathrm{MPa}$ for larch, respectively. These results estimated that was polymerization occurred inside the wood by furfuryl alcohol treated.

The relationship between the dynamic and static MOE of untreated and furfuryl alcohol-treated specimens are shown in Figure 3 and 4, respectively. Figures show that the dynamic MOE was highly correlated with the static MOE. The correlation coefficient was 0.92 for untreated specimens and 0.90 for furfuryl alcohol-treated specimens.

Figures 5 and 6 show the dynamic and static MOE changes according to specific gravity. The dynamic MOE to specific gravity ratio (dMOE/r) and the static MOE to

Table 1. Weight percent gains (WPG), total color changes ( $\Delta \mathrm{E})$, thickness and width swelling, and water absorption (WA) of untreated and furfuryl alcohol-treated (FA) wood

\begin{tabular}{|c|c|c|c|c|c|c|}
\hline Species & Treatment & g & $\Delta \mathrm{E}$ & $\begin{array}{c}\text { Radial direction } \\
\text { Swelling (\%) }\end{array}$ & $\begin{array}{c}\text { Tangential direction } \\
\text { Swelling (\%) }\end{array}$ & WA (\%) \\
\hline \multirow[t]{2}{*}{ Pine } & untreated & - & - & 8.38 & 5.3 & 119.74 \\
\hline & $\mathrm{FA}$ & 0.52 & 48.36 & 2.04 & 2.8 & 39.88 \\
\hline \multirow[t]{2}{*}{ Larch } & untreated & - & - & 6.48 & 5.91 & 68.94 \\
\hline & FA & 0.34 & 53.72 & 1.22 & 3.64 & 22.63 \\
\hline
\end{tabular}

Table 2. Specific gravity (r), natural frequency $\left(\mathrm{f}_{0}\right)$, resonant frequency (f), hardness $\left(\mathrm{H}_{\mathrm{B}}\right)$, static modulus of elasticity (sMOE) and dynamic modulus of elasticity (dMOE) of untreated and furfuryl alcohol-treated (FA) wood

\begin{tabular}{|c|c|c|c|c|c|c|c|c|c|}
\hline Species & Treatment & $\mathrm{r}$ & $\mathrm{f}_{0}$ & $\mathrm{f}$ & $\mathrm{H}_{\mathrm{B}}(\mathrm{MPa})$ & sMOE (MPa) & dMOE $(\mathrm{MPa})$ & $\mathrm{dMOE} / \mathrm{r}$ & $\mathrm{sMOE} / \mathrm{r}$ \\
\hline \multirow[t]{4}{*}{ Pine } & untreated & 0.53 & 784.55 & 809.11 & 1.78 & 7727.2 & 8877.5 & 16770.9 & 14579.2 \\
\hline & (STDEV) & $(0.03)$ & $(46.84)$ & $(47.68)$ & $(0.52)$ & (1365.38) & $(1341.82)$ & (2082.08) & $(2158.03)$ \\
\hline & FA & 0.67 & 770.50 & 796.93 & 4.91 & 8009.3 & 9845.9 & 14818.2 & 12075.0 \\
\hline & (STDEV) & $(0.03)$ & (41.29) & $(42.11)$ & $(2.54)$ & (1058.37) & (1167.20) & (1658.12) & (1573.07) \\
\hline \multirow[t]{4}{*}{ Larch } & untreated & 0.52 & 883.40 & 899.30 & 1.50 & 8978.5 & 10652.1 & 20613.2 & 17648.2 \\
\hline & (STDEV) & $(0.03)$ & (39.64) & $(40.46)$ & $(0.43)$ & $(637.31)$ & $(636.55)$ & (1719.82) & (1766.66) \\
\hline & FA & 0.67 & 825.50 & 840.94 & 2.12 & 9997.4 & 11700.9 & 17344.2 & 14836.6 \\
\hline & (STDEV) & $(0.03)$ & $(24.53)$ & $(25.05)$ & $(0.68)$ & $(564.42)$ & (1003.27) & (1073.05) & (652.38) \\
\hline
\end{tabular}




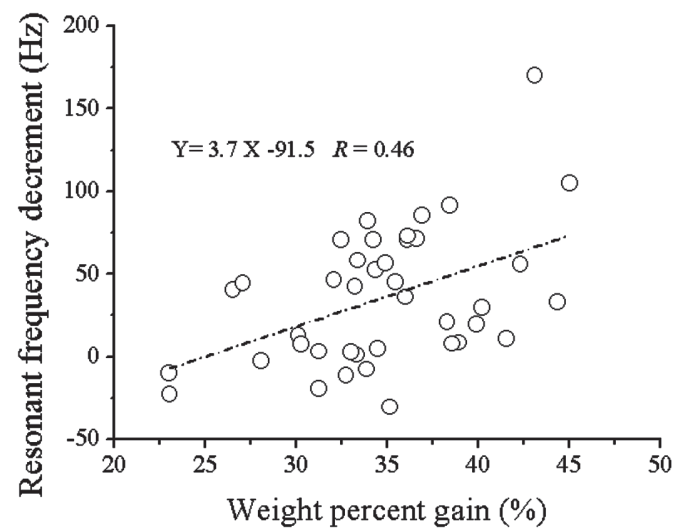

Fig. 2. The relationship between weight percent gain and resonant frequency decrement due to furfuryl alcohol treatment.

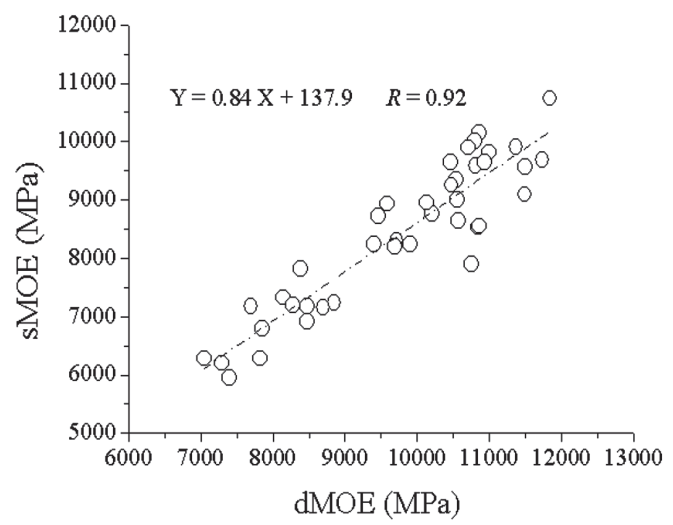

Fig. 3. The relationship between the static modulus of elasticity (sMOE) and the dynamic modulus of elasticity (dMOE) of untreated wood specimens.

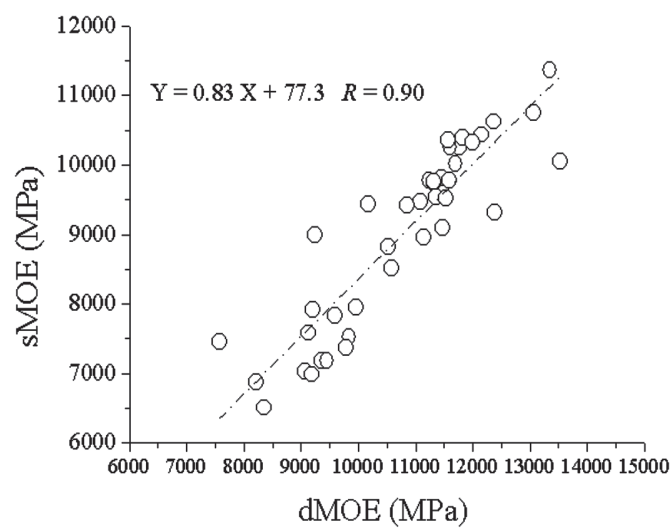

Fig. 4. The relationship between the static modulus of elasticity (sMOE) and the dynamic modulus of elasticity (dMOE) of furfuryl alcohol-treated specimens.

specific gravity ratio (sMOE/r) decreased in furfurylated specimens (Table 2). Norimoto (1992) suggested that higher dMOE/r or sMOE/r ratios are preferred for quality sounding boards for pianos. Therefore, we conclude that the low $\mathrm{dMOE} / \mathrm{r}$ and $\mathrm{sMOE} / \mathrm{r}$ values associated with furfuryl-treated wood could contribute to a decrease in noise if used as flooring materials.

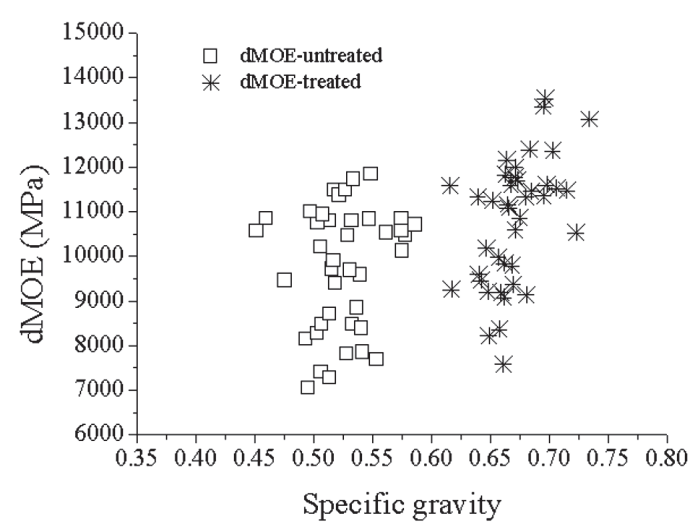

Fig. 5. The relationship between the dynamic modulus of elasticity (dMOE) and specific gravity for untreated and furfuryl alcohol-treated pine and larch wood.

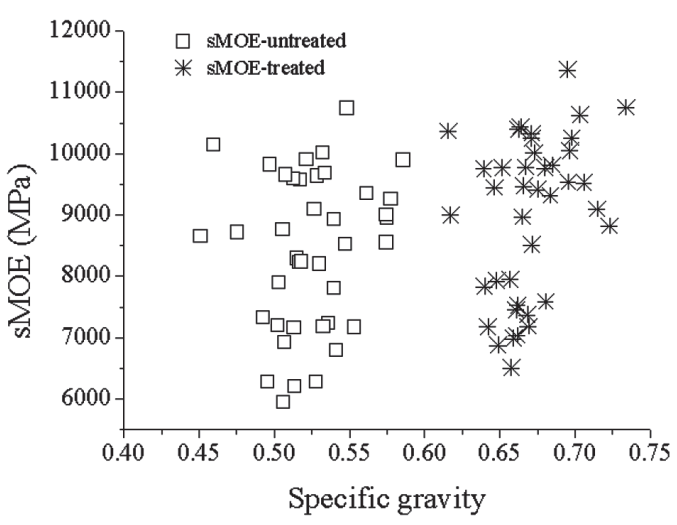

Fig. 6. The relationship between the static modulus of elasticity (sMOE) and specific gravity for untreated and furfuryl alcohol-treated pine and larch wood.

\section{CONCLUSIONS}

Pine and larch wood specimens were treated with $70 \%$ furfural alcohol and cured at a temperature of 130 . We analyzed the changes in physical and mechanical properties, as well as the relationship between the static and dynamic modulus of elasticity. Our study obtained the following results:

Furfuryl alcohol treatment affected the physical and mechanical properties of wood. The color of the specimens changed from yellow to slightly brown. Swelling and water absorption were reduced significantly, and although the natural frequency decreased, the density, hardness, static modulus of elasticity and dynamic modulus of elasticity were all enhanced.

The dynamic modulus of elasticity was highly correlated with the static modulus of elasticity both of furfuryl alcohol-treated specimens and control specimens.

The dynamic MOE to specific gravity ratio (dMOE/r) and the static MOE to specific gravity ratio (sMOE/r) were decreased as a result of furfuryl alcohol treatment. The furfuryl alcohol-treated wood could contribute to a decrease in noise if used as flooring material. 


\section{ACKNOWLEDGEMENTS}

This paper was supported by the research funds of Chonbuk National University in 2014.

\section{REFERENCES}

Cho C. L. 2000 Effects of plantation spacing on the strength variation of Japanese cedar(II): Dynamics and static modulus of elasticity. Forest Products Industries. 19: 19-22

Chuang I. S., G. E. Maciel and G. E. Myers 1984 Carbon-13 NMR study of curing in furfuryl alcohol resins. Macromolecules 17: 1087-1090

Epmeier H, M. Westin and A Rapp 2004 Differently modified wood: comparison of some selected properties. Scand. J. For. Res. 19(5): 31-37

Esteves B, N. Lina and P. Helena 2011 Properties of furfurylated wood (Pinus pinaster). Eur. J. Wood Prod. 69: 521-525

Gonzalez R, R. Martinez and P. Ortiz 1992 Polymerization of furfuryl alcohol with trifluoroacetic-acid - the influence of experimental conditions. Makromol. Chem. 193: 1-9

Gonza lez R, J. M. Figueroa and H Gonza lez 2002 Furfuryl alcohol polymerisation by iodine in methylene chloride. Eur. polym. Journal 38: 287-297

Hill C. 2006 Wood modification: Chemical, thermal and other process: 159-160, John Wiley and Sons. Chichester, Sussex, UK

Kataoka A. and T. Ono 1975 The relations of experimental factors to the vibration and the measuring values of dynamic mechanical properties of wood I. The experimental errors due to the measuring apparatus. Mokuzai Gakkaishi 21: 543550

Lande S, M. Westin and M. Schneider 2004 Properties of furfurylated wood. Scand. J. For. Res. 19(5): 22-30

Lee W-H. and K-H. Hwang 1997 Estimation of the dynamic MOE in woods with resonance frequency. Mokchae Konghak 25(1): 42-49

Maciel G. E., I. S. Chuang and G. E. Myers 1982 Carbon-13 NMR study of cured furfuryl alcohol resins using cross polarization and magic-angle spinning. Macromolecules 15: 1218-1220

Nordstierna L., S. Lande, M. Westin, O. Karlsson and I. Euro 2008 Towards novel wood-based materials: chemical bonds between lignin-like model molecules and poly (furfuryl alcohol) studied by NMR. Holzforsch. 62(6): 709-713

Norimoto M. 1982 Structure and properties of wood used for musical instruments I. On the selection of wood used for piano sound boards. Mokuzai Gakkaishi 28: 407-413

Park H-M. and H-S. Byeon 2006 Measurement of dynamic MOE of 3-ply laminated woods by flexural vibration and comparison with bending strength and creep performances. Mokchae Konghak 34: 46-57 